\title{
EMPIRICAL STUDY OF AN AUTOMATED INVENTORY MANAGEMENT SYSTEM WITH BAYESIAN INFERENCE ALGORITHM
}

\author{
Haiyan Xie ${ }^{1}$, Ranathunga A.M. Sarathchandra ${ }^{2}$ \\ ${ }^{1}$ Associate Professor, Department of Technology, Illinois State University, Normal, Illinois, US \\ ${ }^{2}$ Research Assistant, Department of Technology, Illinois State University, Normal, Illinois, US
}

\begin{abstract}
This research addresses the inefficiency and inconsistency associated with asset tracking and inventory management. This paper focuses on the algorithm and framework of an automated system for large quantities of inventory control, with the features of geographically-widely located facility and heterogeneous assets. Further, the authors investigate two major asset-tracking practices: manual or barcode inventory management system versus automated inventory management system. The authors empirically validate both systems with modeling, simulation, and observation of the system performances. The evidence provides statistically strong support for the improvement of efficiency and accuracy of automated inventory management system, although the impacts of environmental circumstances and human factors suggest that precautions should be taken to minimize the influences of such factors. The proposed automated system is ideal for large quantities of inventory control. Small scale of inventory control depends more on manual inspection or barcode technology. This research provides a possible solution to the growing concerns over asset tracking and protection. In addition, it has the potential to change the facilities management process and policy of the organizations with widely located properties. This empirical study verified the practicability of implementing an automated inventory management system and validated the design by comparing the performances of the manual system and the automated system.
\end{abstract}

Key Words: Inventory management, Performance measurement, Modeling and simulation, Bayesian inference algorithm, and Radio Frequency Identification system

\section{INTRODUCTION}

Inventory management and asset tracking need to record all the durable assets of an institute. Many organizations, i.e. construction companies, are still using manual-tracking systems to manage their inventories, which is very timeconsuming. Implementing an automated system would cut down the time of checking and tracking of assets, which will make services more efficient. This paper studies the algorithm and framework of an automated system for large quantities of inventory control, particularly those facilities whose assets and inventories have the features of geographically-widely located facility and heterogeneous assets. The automated inventory system used by large warehouse or stores could not satisfy the users' needs of those large facilities. The authors deliberated two major asset-tracking practices: manual or barcode inventory management system versus automated inventory management system. The objectives of the research are to investigate the current situations and problems in inventory management, examine the algorithms and structures of an automated inventory management system for those facilities, and suggest a design for such a system to track assets.

It is quite inefficient and labor-intensive for operation managers or project managers to track missing items or check inventories manually or using the barcode technology.
The Radio Frequency Identification (RFID) network system seems to be a practical solution for this problem. RFID technology helps to make sure that the right assets are located at the right place with no discrepancies and errors. The outcome of this research will help to increase the efficiency of inventory management, improve the accuracy and quality of the asset tracking process, and reduce human errors.

The remainder of this paper is organized as follows. The authors first provide the details about the material and equipment used in the research. The authors also describe the research methods of data collection, system verification, and framework design validation. The authors then discuss an integrative literature review on the object localization algorithms and critical system components in the automated inventory management system. To extend the literature review, the authors include a discussion of the context to implement the practical developments of both manual or barcode inventory management system and automated inventory management system. The authors design the hypotheses and test these hypotheses by comparing two datasets gathered from manual system and automated system. In addition, the authors explore the significance of the results. The authors conclude with a discussion that distinguishes the theoretical contributions and managerial 
implications of the work along with possible solutions on limitations and suggestions for future work.

\section{MATERIAL AND METHODS}

To implement the research idea, quotes were invited from Motorola, CSL Products (or Trans Tech Systems), and Strategic System \& technology Corporation for RFID readers and Tags to compare the costs of the implementations. The RFID reader of Motorola KTFX7500US-01 was used to test the design of the proposed system. The reader is a four port reader which has 4 antennas. The operational temperature of the reader should be from $-4^{\circ} \mathrm{F}$ to $+131^{\circ} \mathrm{F}$. Its operational humidity should be from $5 \%$ to $95 \%$. The environmental conditions could affect the accuracy of the readings and the performance of the reader. The Linux operating reader has a flash memory of $512 \mathrm{MB}$ and RAM memory of a $256 \mathrm{MB}$. The frequency of the reader is between $902 \mathrm{MHz}$ and $928 \mathrm{MHz}$. Even though the FX7500 reader can use only four antennas at a time, there are ways to increase the number of antennas that can be used simultaneously for a reader. For example, Wyatt [1] demonstrated a 16-channel high-frequency RFID reader system in his RFID multiplexer system. Since software applications can track the tagged items by using antenna, increasing the number of antennas will help to reduce the budget. The Motorola MC3190 handheld reader has the capabilities of connecting and updating the database via WiFi. It is very useful to get the real-time inventories. AN480CL66100WR is the compatible wide-band antenna for the reader. The antenna has a $3 \mathrm{~dB}$ beam width of $65^{\circ}$ in horizontal and vertical. Omni-ID IQ400 tags are used in this research. The tags are passive tags with the frequency range from $902 \mathrm{MHz}$ to $928 \mathrm{MHz}$. The reading range of the tags is up to 13 feet in a fixed reader and 6.5 feet in a handheld reader. The tags can be used on any metal or liquid surface. The operating temperature range of the tags is from $-20^{\circ} \mathrm{C}$ to $+65^{\circ} \mathrm{C}$. For long-term use, maximum temperature exposure should not exceed $+65^{\circ} \mathrm{C}$.

Since Omni tags have the reading range of 7 feet, the maximum distance between two antennas is kept to 13.9 feet. For example, if equipment or tools are inside a room, the middle of the ceiling of the room is the best location to place antennas. For a large area, multiple readers and multiple antennas will be used. When the authors tested the system design, they installed antennas in the rooms of a property control department building to track facilities. In order to take the maximum benefit of Motorola FX7500 readers, 4 antennas were connected at a time. Then 1 reader was used for 4 cluster rooms. Multiple antennas in a single reader reduce the cost for the project. Another benefit of this system is that tagged assets can be entered to the database by the antenna ID (see Fig -1).

The authors performed field surveys and found that many public libraries implemented systems using RFID technology to track their books. For example, according to the discussion with the Manager of Adult Services and Circulation of the Normal Public Library on September 22nd, 2014, the two major reasons of using RFID systems in the libraries were security and asset tracking. All the media materials, including books, CDs, magazines etc. were tagged with RFID passive tags. There were about 15 readers around the Normal Public Library to track the books. The library purchased the readers and antennas from a company which also provided RFID system solutions. The company supplied and installed RFID readers, performed user training to the library staff about the new system, and developed the management system software. The authors designed and implemented the automated inventory management system using Bayesian inference algorithm and RFID technology. After that, the authors conducted the inventory-checking processes of both the current barcode system and the automated system in an office building for 52 different times each. The authors recorded the number of errors and the time duration to take each inventory. To analyze the collected data, the authors used Minitab-16 software for the calculation.

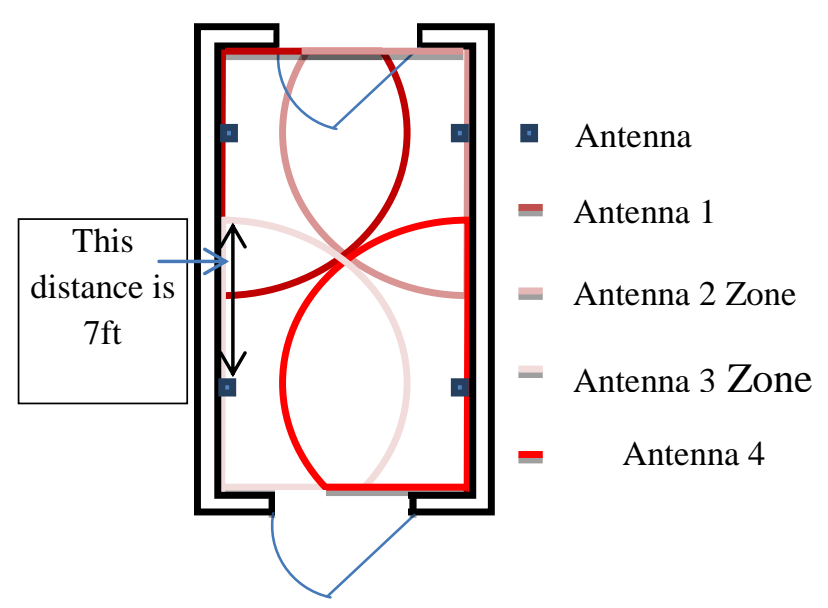

Fig -1: Coverage of exit of a building after creating a RF zone.

\section{THEORY AND CALCULATION}

\subsection{Literature Review}

The main goal of inventory management is to process items and balance the inventory system. Inventory management is a very effective tool for an organization to be efficient in business management [2]. The traditional way of managing inventory is performed by using a pen and a paper to write down the type and quantity of the stock [3]. But errors in inventory records still exist even when the management uses IT systems and product data capturing technologies to improve the inventory systems. Inventory managers have to face inaccuracy of inventory records either at the store or at the warehouse level [4].

In order to improve accuracy of inventory checking, people started using Auto ID technologies. In EPCglobal Report [5], Auto ID technologies are defined as the host of technologies that are used to help machines to identify objects. It is about identifying items, capturing all information about the items, sending and storing those data into a computer with minimal human intervention. 
Barcodes, RFID, biometrics, magnetic strips, Optical Character Recognition (OCR), smart cards, and voice recognition are the common automated identification technologies. According to Schuster [6], the beginning of Auto ID technology was around 1999 with the formation of a consortium research. Barcode technology is one of the most famous Auto-ID technologies in the world right now. In 2004, the number of groceries which were sold with barcodes was over $85 \%$ [7]. The advantages of barcode technology compared to other Auto-ID technologies are: easy to use, less expensive, and widely accepted. There are a few disadvantages of barcode technology as well. For example a barcode scanner has to scan each barcode individually. Barcode scanner has limited data carrying capacity. It generally needs human involvement or direct connection with computer database for data transfer. Wireless scanner is easy to get damaged, has less security, and is low in reliability. In case if a barcode is damaged, there is no way to scan the information about the product.

RFID is an automated identification or data capturing method that uses radio waves to activate a response from a device attached to an item [8, 9]. This automatic identification technology is to identify the tagged objects and to collect the relevant data in a non-contact manner. RFID transponders (tags) are in two forms and hybrids. One form is passive tags which have limitations on data storage and small in size. Passive tags are powered and communicated by the reader [10]. The tag itself does not need a separate power source [11]. The other format of RFID tags is active tags. An active tag contains a power source such as a battery [11]. The power source is to power the tag. It allows the reader to respond quickly when the signals are received. Ngai and colleagues [12] discussed the different areas of implementations of RFID technology, such as warehouse management, asset tracking, retail, and medical care.

RFID technology is based on the radar concept. First a signal is sent by the RFID reader to the transponder. Then the transponder reflects a signal back or broadcasts a signal. An RFID system has three basic components. They are a transponder (tag), transceiver (reader), and the back-end database [11]. When the RFID tags move within the readable range of an RFID reader's radio field, each tag responds by reporting its identification data to the reader [13]. Then the transceiver reads the data and passes the data on to enterprise applications such as enterprise resource planning, customer relationship management, supply chain management systems, or other use in synchronization operations [14]. Currently, the manufacturing processes for passive RFID tags are simplified and automated, which decreases the production cost vastly. But the adoption rate of RFID technology is not as fast as what people expected, due to the high investment on initiation and the lack of RFID standard [15].

Another challenge of RFID implementation is the mathematical model for localization of the variation of the radio frequency signals in space. Zhou and Shi [16] studied several RFID localization algorithms for the estimation of the distance between an RFID tag and a reader, if the received signal strength is known. They compared the existing localization techniques, summarized the localization algorithms of mathematically models for RFID localization, and focused on multilateration algorithm and Bayesian inference algorithm. Multilateration uses the distances between a target and its reference objects (with known coordinates) to estimate the coordinates of the target object. Bayesian inference utilizes statistical evidence or observations to infer the probability that a hypothesis may be true [16]. Both multilateration algorithm and Bayesian inference algorithm can be used for RFID localization. Both algorithms can calculate the coordinates of the target node. In the research, the authors implemented the Bayesian inference algorithm.

Multilateration algorithm has the condition as follows:

- $\quad \mathrm{n}$ reference nodes $\mathrm{R}_{\mathrm{k}}, \mathrm{k}=1,2, \ldots, \mathrm{n}$ with known coordinates $\left(\mathrm{x}_{\mathrm{k}}, \mathrm{y}_{\mathrm{k}}\right)$;

- $\quad$ Target node $\mathrm{T}$ with unknown coordinates (x, y);

$\mathrm{D}_{\mathrm{k}}, \mathrm{k}=1,2, \ldots, \mathrm{n}$, the authors obtain equation group (1).

$$
\begin{aligned}
& D_{1}^{2}=\left(x-x_{1}\right)^{2}+\left(y-y_{1}\right)^{2} \\
& D_{2}^{2}=\left(x-x_{2}\right)^{2}+\left(y-y_{2}\right)^{2} \\
& D_{n}^{2}=\left(x-x_{n}\right)^{2}+\left(y-y_{n}\right)^{2}
\end{aligned}
$$

To linearize the above equation group (1), the authors use the first equation in the group and subtract each of the rest equations. Thus, the authors obtain equation group (2).

$$
\begin{aligned}
B_{i 1}=\frac{1}{2}\left(x_{1}^{2}-x_{i}^{2}+y_{1}^{2}-y_{i}^{2}+r_{1}^{2}-r_{i}^{2}\right), i & =2,3, \ldots, n \\
\left(x_{1}-x_{2}\right) x+\left(y_{1}-y_{2}\right) y & =B_{21} \\
\left(x_{1}-x_{3}\right) x+\left(y_{1}-y_{3}\right) y & =B_{31} \\
\left(x_{1}-x_{n}\right) x+\left(y_{1}-y_{n}\right) y & =B_{n 1}
\end{aligned}
$$

The matrices forms of the above equations are as follows:

$$
\begin{gathered}
A=\left(\begin{array}{cc}
x_{1}-x_{2} & y_{1}-y_{2} \\
x_{1}-x_{3} & y_{1}-y_{3} \\
\ldots & \ldots \\
x_{1}-x_{n} & y_{1}-y_{n}
\end{array}\right), \\
X=\left(\begin{array}{c}
x \\
y
\end{array}\right), B=\left(\begin{array}{c}
B_{21} \\
B_{31} \\
B_{n 1}
\end{array}\right) .
\end{gathered}
$$

Coordinates of $\mathrm{T}=\operatorname{Min}\|\mathrm{AX}-\mathrm{B}\|^{2}$

Bayesian inference algorithm has the condition as follows:

- Target node receives signals of $n$ reference nodes $S_{i}, i=$ $1,2, \ldots, n$

- Target node $\mathrm{T}$ with unknown coordinates (x, y)

The probabilities of $S_{i}$ are independent of each other, in which case, the system satisfies Markov condition.

$\alpha$ is a normalizing factor to ensure the sum of probability $\mathrm{P}$ satisfies the following condition:

$\mathrm{P}\left((\mathrm{x}, \mathrm{y}) \mid \mathrm{S}_{1}, \mathrm{~S}_{2}, \ldots, \mathrm{S}_{\mathrm{n}}\right)$ to be one. 
For Coordinates of T,

$\mathrm{P}\left((\mathrm{x}, \mathrm{y}) \mid \mathrm{S}_{1}, \mathrm{~S}_{2}, \ldots, \mathrm{S}_{\mathrm{n}}\right)=\alpha \mathrm{P}\left(\mathrm{S}_{\mathrm{n}} \mid(\mathrm{x}, \mathrm{y})\right) * \mathrm{P}\left((\mathrm{x}, \mathrm{y}) \mid \mathrm{S}_{1}, \mathrm{~S}_{2}, \ldots\right.$, $\left.\mathrm{S}_{\mathrm{n}-1}\right)$

RFID reading range specifies the distance of reading tags. Passive tags have about 20 feet of read range and some active tag systems can communicate from 20 meters to 100 meters [17, 18]. Another advantage of RFID is that an RFID reader can read tags faster than a barcode scanner. According to Teicholz [18], the speed of RFID readers made them to read up to 40 or more tags per second. In contrast, ordinary barcode system took 0.5 second or more to successfully complete a single read. The speed of barcode reading depends on how fast a human being can operate it, because most of the times it requires someone to use the reader close to the tag [9]. The quality and accuracy of RFID tag reading is beyond barcode [11]. Other than those main advantages, ability of programming tags as customers wanted, capacity of storage, survivability (i.e. environmental friendly tags), ability of reading multiple tags simultaneously, and serialization (i.e. unique identification) also bring the RFID technology forward [9, 11]. Table 1 shows the summary of the aforementioned discussion and comparison of barcode and RFID technologies.

Table -1: Barcode vs. RFID [19]

\begin{tabular}{lll}
\hline Data & Barcode & RFID \\
$\begin{array}{l}\text { Reading } \\
\text { Capabilities }\end{array}$ & $\begin{array}{l}\text { One at a time; } \\
\text { Require a short; } \\
\text { distance to read; } \\
\text { Should be clean; } \\
\text { Cannot be } \\
\text { damaged }\end{array}$ & $\begin{array}{l}\text { Many at a time; } \\
\text { the line of sight; }\end{array}$ \\
$\begin{array}{lll}\text { Easy } \\
\text { Implementation identity }\end{array}$ \\
Cost & $\begin{array}{l}\text { Cheap } \\
\text { Can copy or } \\
\text { change }\end{array}$ & $\begin{array}{l}\text { Complicate } \\
\text { Cannot access data } \\
\text { easily; } \\
\text { Cannot copy or } \\
\text { change }\end{array}$ \\
\hline
\end{tabular}

\subsection{Calculation Method Used In the Research}

The assumption made in the study is that equipment handling temperature and all environmental conditions are the same in all tests. This assumption is made to assure that the results of the tests will not be affected by environmental factors.

Definitions of Terms are as follows:

H0 Null Hypothesis: $\mathrm{T}_{0}-\mathrm{T}_{1}=0$

H1 Hypothesis: $\mathrm{T}_{0}-\mathrm{T}_{1} \neq 0$

$\mathrm{T}_{0}$ - Time to take an inventory in the current system

$\mathrm{T}_{1}-$ Time to take an inventory with the new RFID system

\section{MODELING, SIMULATION, AND RESULTS}

\subsection{Observation and Modeling}

After the surveys and the conversations with the directors and managers at different organizations, the authors studied on the misplacement situations of those organizations. The property control in FM is having some troubles with misplaced or lost property. After several meetings and discussions with the managers, the authors were able to determine a few critical areas where RFID systems could be implemented. Because of the occurrences of lost assets, the need to protect assets, and the inefficiency in the current inventory process, the authors selected asset management for this study.

The scenario of the current inventory system is shown as a flow chart in Fig. 2. At the chosen organization, the department director or office manager has the responsibility of collecting a record of data for the current inventory system. In the current process, the directors of all the 154 departments assign individuals to inspect inventories. There are 154 workers doing inventories once a year. In the inventory process, each worker's duties include the following tasks: go to rooms, check inventories, record data, and send the data to the manager. Then the manager sends those inventory sheets to the Property Control Manager (PCM).

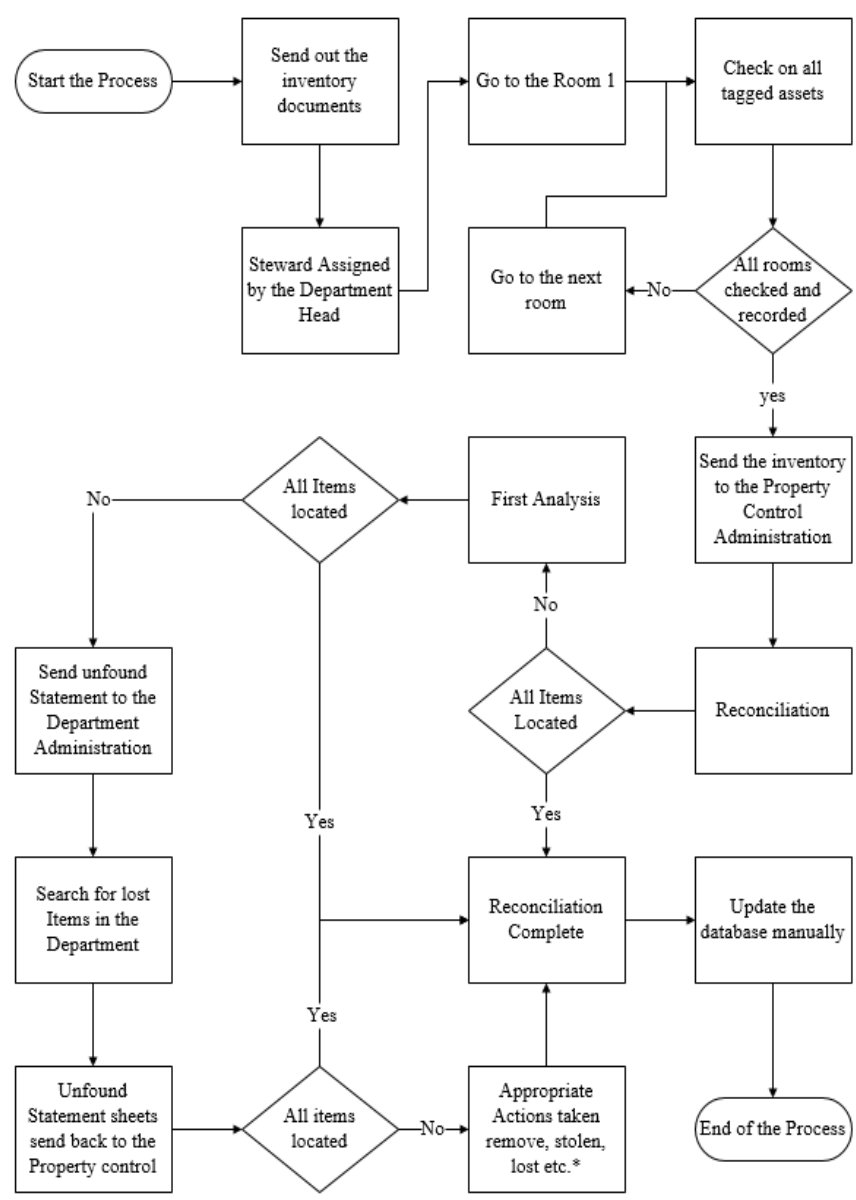

Fig -2: Flow chart of the current inventory system (* the actions include filing a report of the items). 
The current item tagging process is handled by the Property Control Center. After an item is purchased, office manager has to inform the Property Control Center about the new item by sending a voucher to the PCM. As shown in the Fig. 3, the PCM reviews the voucher and set up a time to tag the new item. Then a PCM assigns a worker to go and tag the items. After the worker tags the item, the office manager will fill a form with all the details of the new item, including the location of the item in the office.

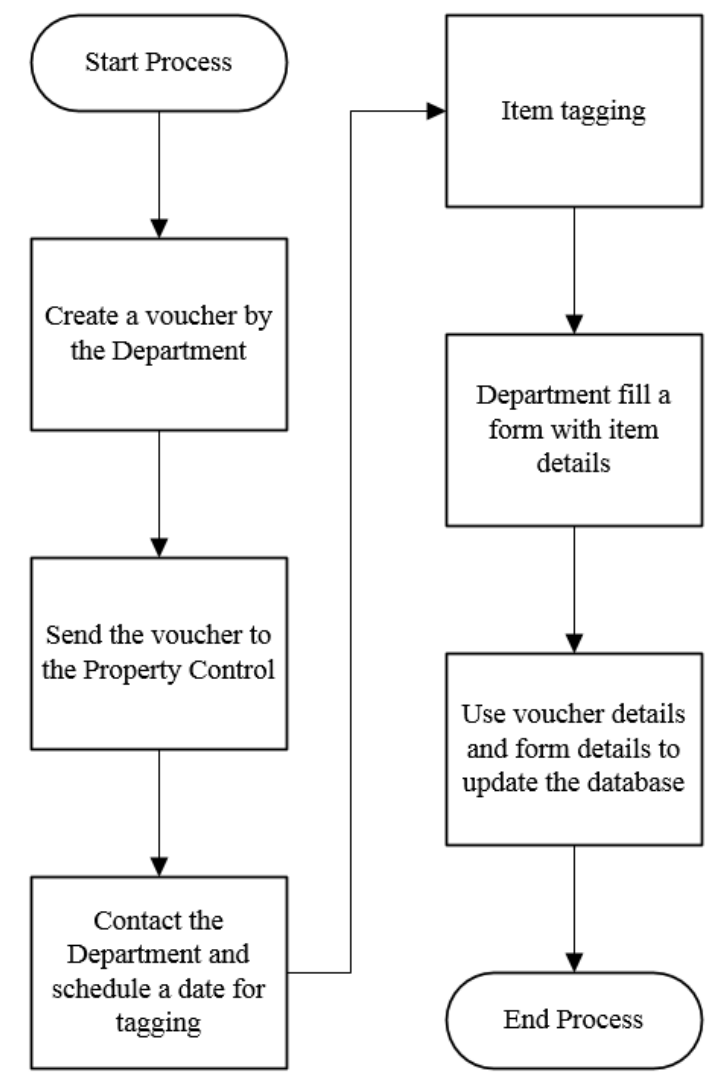

Fig -3: Current item tagging process.

The current process has advantages and disadvantages compared to a fully automated system. The main advantage is that the person who is recording the inventory knows what items in that area are missing. In the pharmaceutical industry this method is called "Visual Inventory Control Method" (VICM) because the inventory recorder visually observes the item and notes the data [20]. An inventory taker can prove that an item is missing because he or she actually goes to each room and observes each item to record the data. Cost is another advantage for the VICM. In a manual system, typically the only cost is the pay to the workers.

The main weakness of the current system stems from human errors. The current system is a manual system. Human factor affects the accuracy of the inventory. Another disadvantage is the time to take inventory. In the current system, it can take up to 4 or 5 days to complete the inventory. According to the PCMs, they have a 3-month window to take the inventory. But some inventories are returned after 2 months of the due date. The unpredictable real-world situations make the manual system inefficient. The third disadvantage is that the current inventory system is conducted only once a year. The system cannot receive real time data. It is easier to track and find a misplaced item right after it was relocated than search for it after several months.

In this research, an RFID inventory system is implemented to use hand held readers to take inventories. All valuable assets are tagged with positive RFID tags. The process of this design is displayed in Fig. 4 as a flow chart diagram. The RFID inventory process starts with assigning an inventory checker his or her responsibility. Then the person goes to the first room to scan the room tag and scan all the assets in the room.

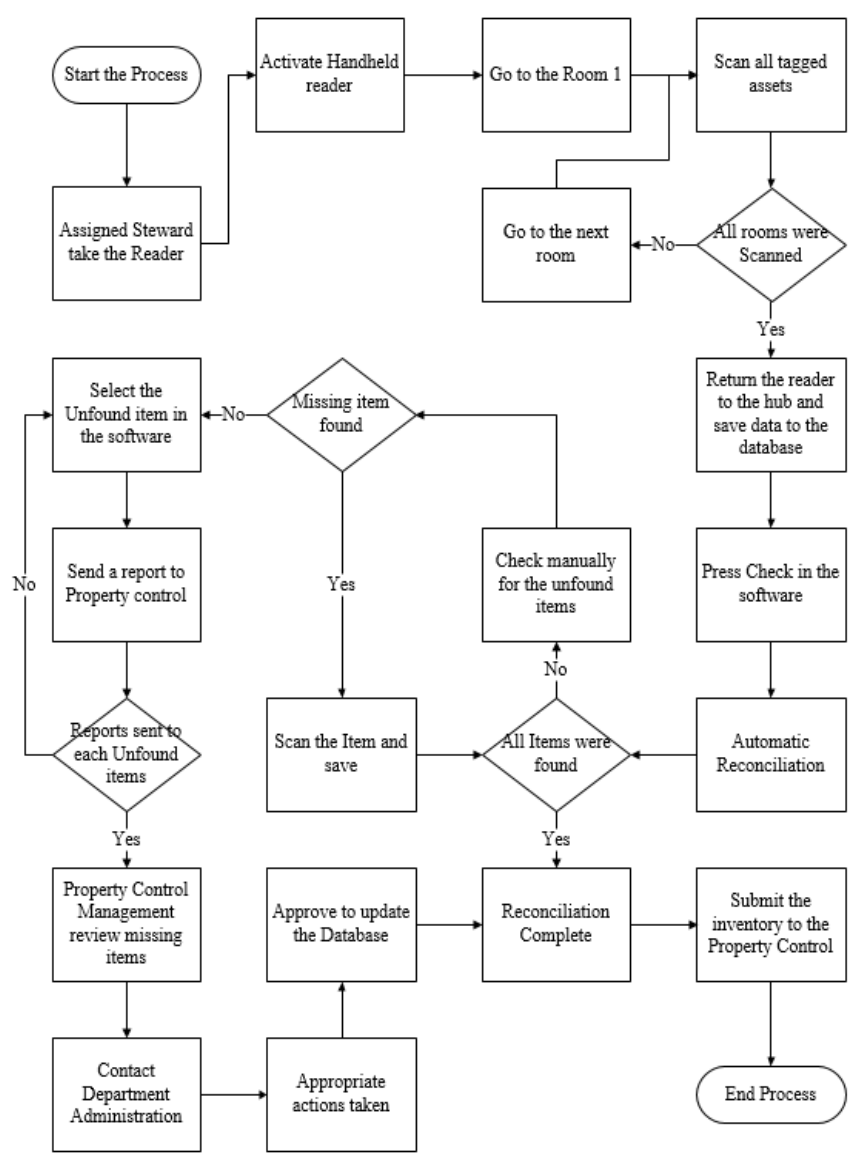

Fig -4: Flow chart diagram of the RFID inventory system.

At the software side, after the room tag is scanned, a list of assets which should be in that room will be shown on the hand held reader's screen. Hand held readers have the ability to record data because it has a built-in memory. The data will be stored in the handheld reader until they are transferred to the database through $\mathrm{Wi}-\mathrm{Fi}$ in the building. If $\mathrm{Wi}-\mathrm{Fi}$ is available, the reader directly sends the data to the database and updates the system at the same time.

\subsection{Implementation}

If $\mathrm{Wi}-\mathrm{Fi}$ is not available at the place where inventory is checked, an inventory checker has to save data from the scanner to the database after scanning all rooms and returning the scanner to the hub. Fig. 5 shows the data saving process. When the inventory checker clicks on the save button, the system automatically starts the 
reconciliation process. All the missing items in the inventory will be shown on the box below the check button in the user interface. The item's tag ID and tag name will also be displayed as shown in the Fig. 6 . The reconciliation process is fully automatic. It is easy to scan tags because RFID reader can read tags from a certain distance (e.g. 7 feet), which reduces the time to take an inventory. Because of the easiness of taking the inventory, PCM can take inventories more than once a year.

\subsection{Tests}

The authors collected performance data of the current barcode inventory system under 52 different situations. With the same environmental conditions, the authors collected 52 testing results for the performance of the RFID system as well. According to the observations, it took longer to check inventory the first time in both barcode system and RFID system, because of the tasks to identify the items, tag them, and look for the missing items. After the first inventory process in both systems, the learning curves had steep drop. Time durations recorded were converted to minutes to compare results.

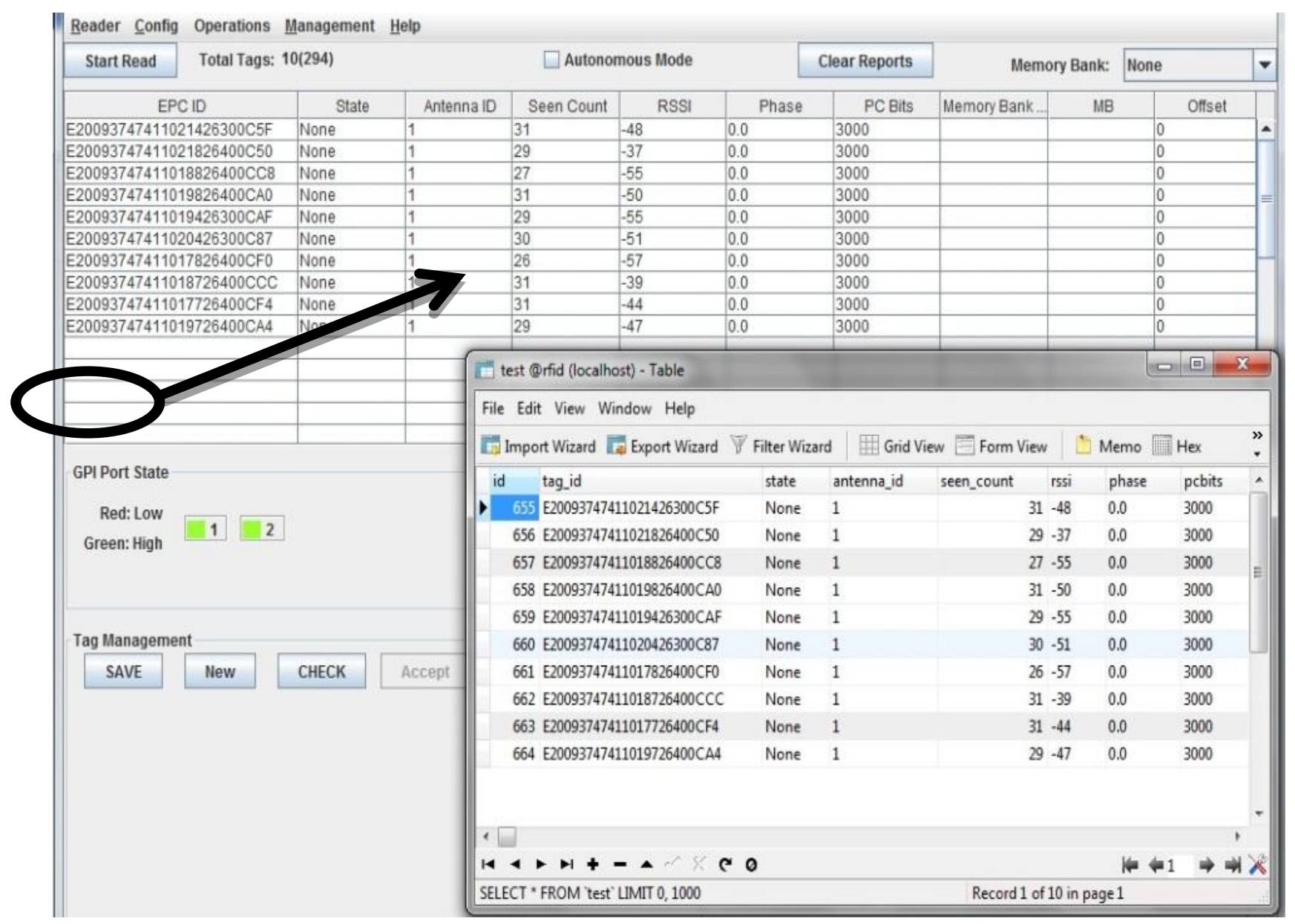

Fig -5: Data saving process

\begin{tabular}{|c|c|c|c|c|c|c|}
\hline CHECK & Accept & Send Mail & Submit & Tag ID & Tag Name & image \\
\hline & & & & \multicolumn{3}{|c|}{\begin{tabular}{|l|l|l} 
E200937474110177264... & Sony Camera \\
\end{tabular}} \\
\hline & & & & E200937474110214263.. & Laser Printer & \\
\hline & & & & E200937474110188264.. & Desk w/Single Ped & \\
\hline & & & & E200937474110178264.. & Table & \\
\hline & & & & E200937474110218264.. & Laptop & \\
\hline & & & & E200937474110198264.. & RFID reader & \\
\hline & & & & E200937474110204263.. & RFID antenna & \\
\hline & & & & E200937474110194263.. & Chair, lounge & \\
\hline
\end{tabular}

Fig -6: Missing item list 


\subsection{Results}

\subsubsection{Accuracy Comparison}

Per their observations, the authors found that the accuracy of the current inventory system is affected by the occurrences of the following 4 types of mistakes as shown in Table 2. (1) Route mistake: It happened when the inventory takers did not follow the shortest-possible route or changed the route of inventory process arbitrarily, which caused the inefficiency in walking distance between inventory items. (2) Checking a wrong item: This mistake happened when the inventory takers accidentally checked the wrong items. The mistake caused a missing report to be issued from the RFID system. (3) Forget checking an item: Occasionally, inventory checkers might leave some items unchecked. (4) Time-recording mistakes: In the manual or barcode system, the authors read time by using a stopwatch. There were two errors caught because of mistakes in reading the stopwatch. The structure of the inventory list provided by the Property Control Management was unorganized, which caused some of the mistakes in the tests. Overall, the authors checked 1196 items when testing the barcode system. There were 13 wrong items checked and 6 forget-to-check items out of 1196 readings.

Table -2: Number of Errors in Each System

\begin{tabular}{|c|c|c|}
\hline \multicolumn{3}{|c|}{$\begin{array}{ll}\text { Total number of items recorded per inventory } & =23 \\
\text { Number of inventories in each system } & =52 \\
\text { Total number of items recorded in each system }= \\
23 \times 52=1196\end{array}$} \\
\hline Mistake type & $\begin{array}{l}\text { Manual } \\
\text { Inventory }\end{array}$ & $\begin{array}{l}\text { Automated } \\
\text { Inventory }\end{array}$ \\
\hline Route & 5 & 4 \\
\hline Wrong Item check & 13 & 0 \\
\hline Forget to check an item & 6 & 0 \\
\hline Time recording mistake & 2 & 0 \\
\hline Total & 26 & 4 \\
\hline Accuracy of the system* & $97.82 \%$ & $99.66 \%$ \\
\hline
\end{tabular}

\subsubsection{Efficiency Comparison}

According to the collected data paired t-test was conducted in Minitab 16. Results of the analysis are shown in Fig. 7. Comparing the two inventory systems, the time used by the manual inventory had a significantly higher average time $(\mathrm{M}=9.704, \mathrm{SD}=2.174)$ than the time used by the RFID inventory $(\mathrm{M}=1.593, \mathrm{SD}=0.847), \mathrm{t}(51)=(41.75), \mathrm{p}=$ 0.0000 . This results leads to reject the null hypothesis at the 95\% confidence level, which means that statistically the RFID inventory system is more efficient with $95 \%$ confidence level.

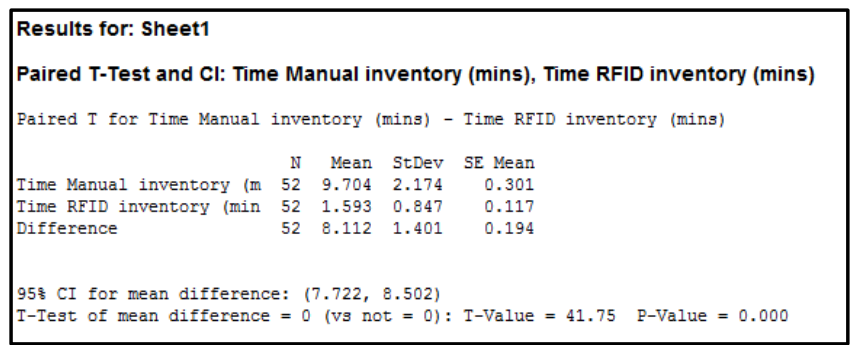

Fig -7: Results of T-test analysis.

The tests on the barcode inventory system and the RFID inventory system revealed several potential improvements that could enhance the efficiency and increase accuracy of the current inventory system. It is also possible to reduce implementation costs of the automated inventory system. The current inventory process is an annual procedure and it takes 3 months (180 calendar days, 67.5 working days, or 540 working hours) to complete. In the current barcode system, the average time for inventory checking in a department was 22.7 working hours. According to the surveys and analysis, the 517.3 hours difference included lead time, waiting time, time spent in walking between buildings, or time spent on asset localization. The application of the automated model could reduce the idling time dramatically. Daily inventory checking becomes possible with the automated system.

\section{DISCUSSION}

During the research, the authors implemented the Bayesian inference algorithm as the localization method and designed the RFID system for geographically-widely located facility and heterogeneous assets. The authors utilized the RFID system to track assets and compared the system performance with that of the barcode/manual system. The outcomes of this research indicated with statistical significance that the RFID system can increase the efficiency of inventory management, improve the accuracy and quality of the asset tracking process, and reduce human errors. The applied RFID system reduced the man power to conduct the inventory control and track the number of lost items.

Many FM offices have implemented RFID technologies to accommodate inventory control and asset tracking. Using on the research results, the authors explained system design to the FM office of the chosen organization and described the possible benefits that an RFID inventory system can achieve for them. The FM directors and managers made the decision to: (1) restructure the inventory list of the current manual or barcode system to achieve better efficiency; (2) educate the inventory checkers of the new structure of the inventory list and help them design the shortest route in the inventory checking process; (3) defer the implementation of the RFID inventory system because of the institute's budget limitations; (4) formulate a financial plan for future design and implementation of such an automated system; and (5) increase commitment to inventory tracking and asset protection. The major concern of the implementation of such an automated system is that the initial cost of the system is substantial and the investment recovery time is noteworthy. 
During the 4 or 5 years of recovery time of the technology, new and improved technology might emerge, which will put the institute in a disadvantaged situation.

\section{CONCLUSIONS}

This research studied the algorithm and method of an automated RFID system which can help the FM managers to make sure that the right assets are located at the right place with no discrepancies and errors. It can improve the accuracy, efficiency, and reliability of the inventory management system. The research project has the potential to be expanded to various areas, such as construction companies with multiple jobsites, large government building complex, or inventory management system in healthcare organizations, education institutes, and other in-service organizations. When employing the RFID inventory system on a daily basis or weekly basis, the RFID system has convenience and advantages over the barcode or manual inventory systems.

\section{ACKNOWLEDGEMENT}

The authors would like to thank Dr. Klaus Schmidt and Dr. Anu Gokhale for their contribution to this research.

\section{REFERENCES}

[1]. Wyatt, J. (2012). TRF7960A RFID multiplexer example report. Texas: Texas Instruments.

[2]. Adeyemi, S., \& Salami, A. (2010). A tool of optimizing resources in a manufacturing industry. (K.-R. 2010, Ed.) Inventory management: A tool of optimizing resources in a manufacturing industry: a case study of Coca-Cola Bottling Company, Ilorin Plant, 135-142.

[3]. Chen, Y. Y.; Jan, J. K.; Tsai, M. L.; Ku, C. C., \& Huang, D. C. (2012). On the security of RFID-based monitoring mechanism for retail inventory management. KSII Transactions on Internet and Information Systems, 6(2).

[4]. Rekik, Y., \& Sahin, E. (2012). Exploring inventory systems sensitive to shrinkage - Analysis of a periodic review inventory under a service level constraint. International Journal of production Research, 50(13), 3529-3546.

[5]. EPCglobal. (2004 - 2008). EPC radio-frequency identity protocols class-1 generation-2. EPCglobal Inc.

[6]. Schuster, E. W. (2005). Auto-ID technology: Creating an intelligent infrastructure for business. Cambridge, MA: Massachusetts Institute of Technology.

[7]. Shepard, S. (2005). RFID: radio frequency identification. McGraw- Hill Professional.

[8]. Bayraktar, A., Y1lmaz, E., \& Erdem, S. (2011). Using RFID technology for simplification of retail processes. In Turcu, C. (Ed.) Designing and deploying RFID applications. Retrieved from http://www.intechopen.com/books/ designing-and-deploying-rfid-applications/using-rfid- technology-for-simplification-of-retail-processes

[9]. Brown, D. (2007). RFID implementation. New York: McGraw-Hill Company.

[10]. Kaur, M., Sandhu, M., Mohan, N., \& Sandhu, P. (2011). RFID technology principles, advantages, limitations \& its applications. International Journal of Computer and Electrical Engineering, 151-157.

[11]. Visich, J., Suhong, L., \& Khumawala, B. (2007). Enhancing product recovery value in closed-loop supply chains with RFID. Journal of Managerial Issues, 436-452.

[12]. Ngai, E., To, C. K., Moon, K. K., Chan, L., Yeung, P. K., \& Lee, M. C. (2009). RFID systems implementation: a comprehensive framework and a case study. International Journal of Production Research, 48(9), 2583-2612.

[13]. Heim, G. R., Wentworth, W., \& Xiaosong, P. (2009). The value to the customer of RFID in service applications. Social Science Research Network, 40(3), 37.

[14]. Dutta, A., Lee, H., \& Whang, S. (2007). RFID and operations management: Technology, value, and incentives. Production and Operations Management, 16(5).

[15]. Matta, V., \& Moberg, C. (2006). The development of a research agenda for RFID adoption and effectiveness in supply chains. Issues in Information Systems, 7(2), 246-251.

[16]. Zhou, J., \& Shi, J. (2009). RFID localization algorithms and applications - A review. Journal of Intelligent Manufacturing, 20(6), 695-707. doi:10.1007/s10845-008-0158-5

[17]. Weinstein, R. (2005). RFID: A technical overview and its application to the enterprise. IT Pro, 27-33.

[18]. [18]. Teicholz, E. (2013). Technology for facility managers. John Wiley \& Sons.

[19]. Hunt, D. V., Puglia, A., \& Puglia, M. (2007). RFID guide to Radio Frequency Identification. Hoboken New Jersey: John Wiley \& Sons.

[20]. Chisholm-Burns, M. A., Vaillancourt, A. M., \& Shepherd, M. (2014). Pharmacy management, leadership, marketing, and finance. Burlington, MA: John \& Barlett Learning LLC.

\section{BIOGRAPHIES}

Dr. Xie has over 12 years of teaching experience in universities and over 5 years of industry experience. She is a licensed PE, CPC, and CDT. Her research focuses on Smart City, Modeling, Simulation, and Control, etc. 